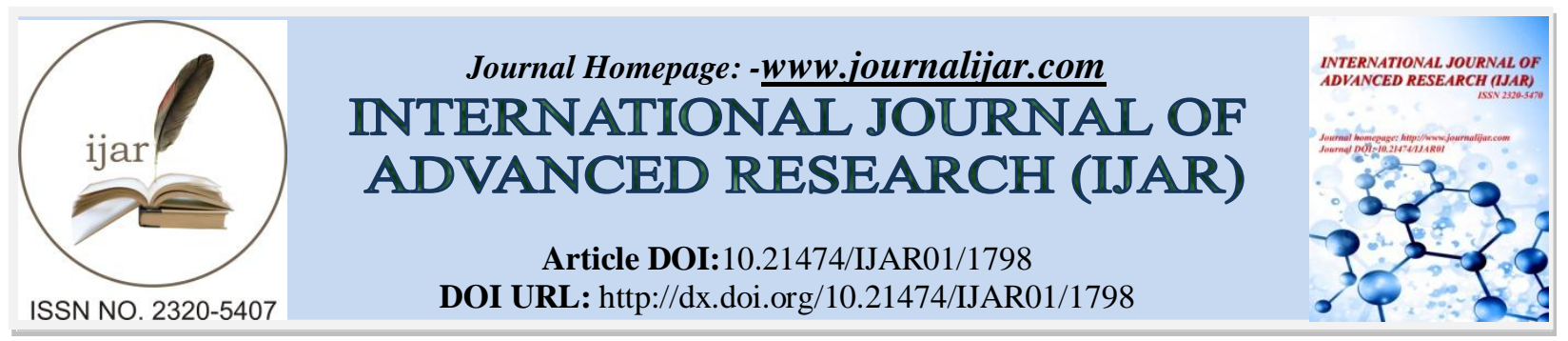

RESEARCH ARTICLE

\title{
INCIDENCE OF BARIATRIC SURGERY AMONG SAUDI POPULATION, ACROSS SECTIONAL STUDY.
}

\author{
Sultan T. Almutrafi ${ }^{1}$, Sultan I. Almalik ${ }^{1}$, Waleed M. Almejlad ${ }^{1}$, Musaed Alkhuraisi ${ }^{1}$, Abdulraouf Almajhad ${ }^{1}$, \\ and Yazid M. Alotaibi². \\ 1. Qassim university, college of medicine- K.S.A. \\ 2. Prince Sattam Bin Abdulaziz university, college of medicine.
}

\section{Manuscript Info}

...........................

Manuscript History

Received: 12 August 2016

Final Accepted: 22 September 2016

Published: October 2016

\section{Abstract}

Bariatric surgery is a common operation done among Saudis. Numbers of patients underwent for this surgery is still increasing which give us a hint of people affecting by obesity in our society. In our study, will know what is the peak age people affecting by obesity and did this operation, percentage of these patient had travel to other country to do it. In this study we are going to know also what is the percentage of people who underwent for this surgery without indication according to American Society of Metabolic and Bariatric Surgery. It expected that, most of them do not know what are the indication and done it without indication. We hope that by reading of this study, people know better about this surgery including indications.

Copy Right, IJAR, 2016,. All rights reserved.

\section{Introduction:-}

Bariatric surgery is a common surgery nowadays. ${ }^{1}$ It also called obesity surgery or metabolic surgery. Bariatric operations involve either restriction of caloric intake or malabsorption of nutrients or both. ${ }^{2}$ Bariatric surgery has many types including Lap band, Roux-en-Y gastric bypass, duodenal switch and vertical sleeve which all aim to decrease stomach content and cause malabsorption to loss the weight. ${ }^{3}$ During the 1950 s, operations were first performed to treat severe hyperlipidemia with associated obesity. ${ }^{4}$ These operations were ileocolic bypass to limit absorption but there were many complications including liver failure. ${ }^{5}$ The first laparoscopic adjustable gastric banding operation was done in 1994 by Belachew. ${ }^{6}$ Many cases reported that, patients may develop a bowel obstruction after laparoscopic gastric bypass which requires essential surgical intervention. ${ }^{7}$ Bariatric surgery consider the most effective method for decreasing morbidity and mortality of obesity which is the second most common death in the United States. ${ }^{8}$ The degrees of obesity are defined by body mass index(BMI). BMI=weight $(\mathrm{Kg}) /$ height $(\mathrm{m}) 2{ }^{9}$

\begin{tabular}{|l|l|}
\hline Classification & BMI \\
\hline Normal range & $18.5-24.9$ \\
\hline Pre-obese & $25-29.9$ \\
\hline Obese class 1 & $30.0-34-9$ \\
\hline Obese class 2 & $35.0-39.9$ \\
\hline Obese class 3 & 40 and above \\
\hline
\end{tabular}




\section{Patients and Method:-}

This research contains 100 sampleswere done among only Saudis, to identify percentage who underwent for this surgery without indication and by their own choice. Questionnaire was online, which answered by patients themselves, then analyzed by using SPSS program. The questionnaire language was Arabic, then translated to English when using SPSS for data analysis and publishing.

\section{Results:-}

Gender

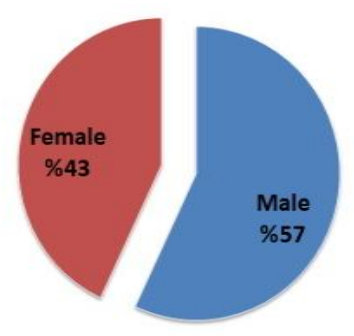
Did anyone advice you to do bariatric surgery ( other than doctors ) ?

Did anyone advice you to do bariatric surgery ( other than doctors) ?

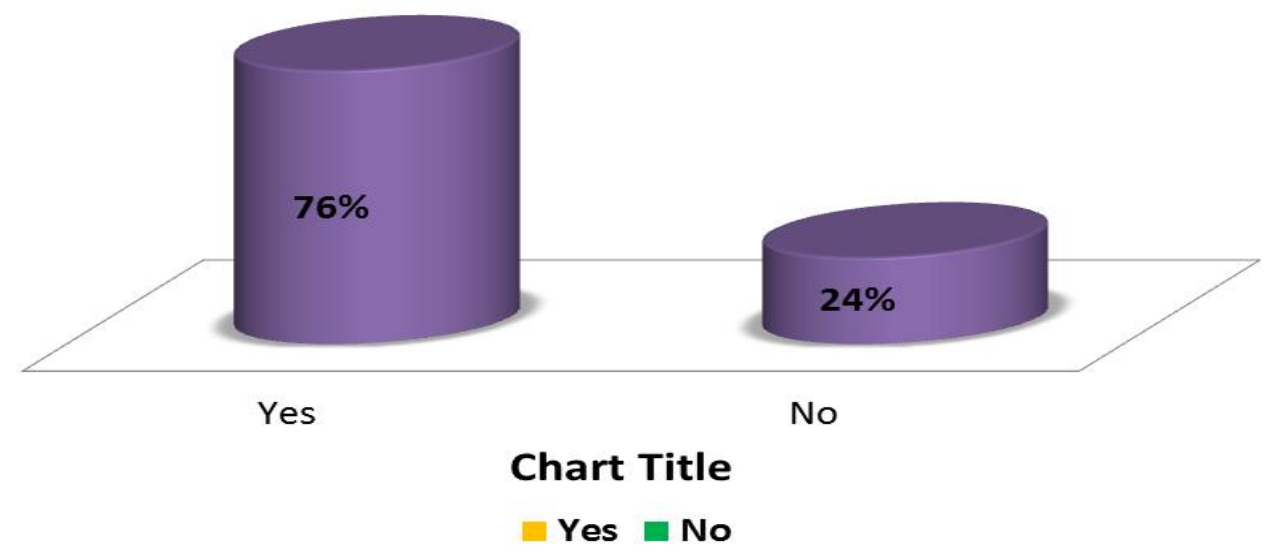

$97 \%$

$3 \%$

Do you have heart disease? 


\section{Chart Title}

a Yes No

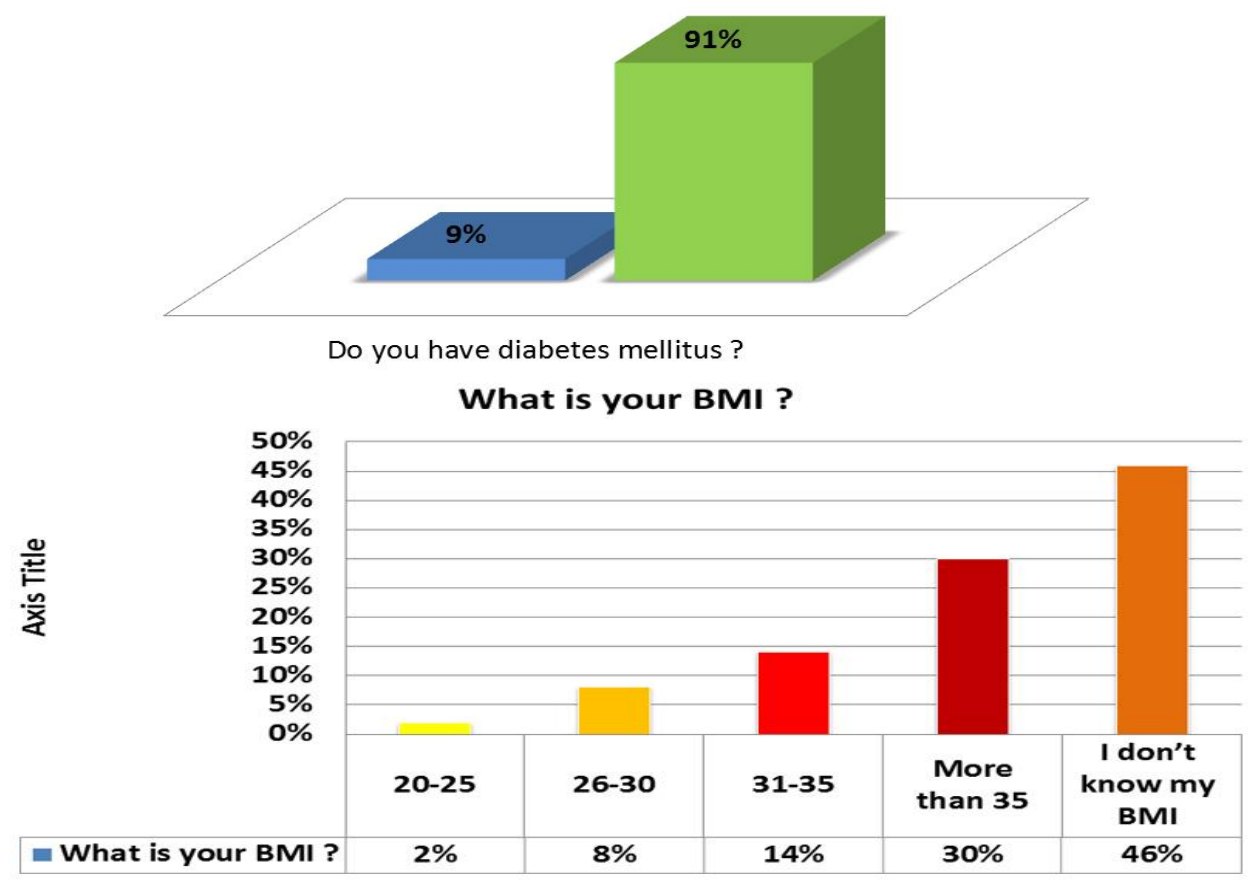

Did any doctor advice you to do bariatric surgery before ?

Did any doctor advice you to do bariatric surgery before ?

$59 \%$

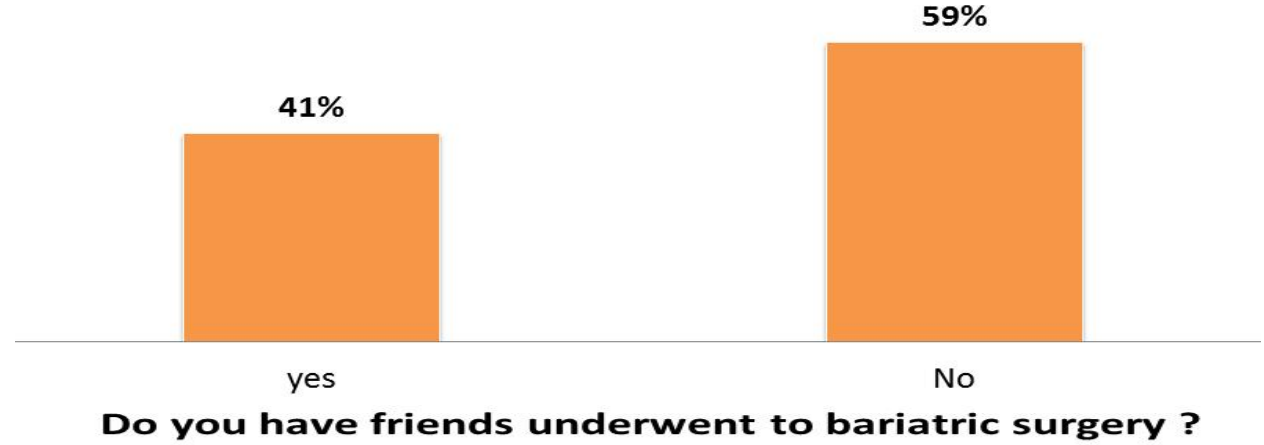

Do you have friends underwent to bariatric surgery?

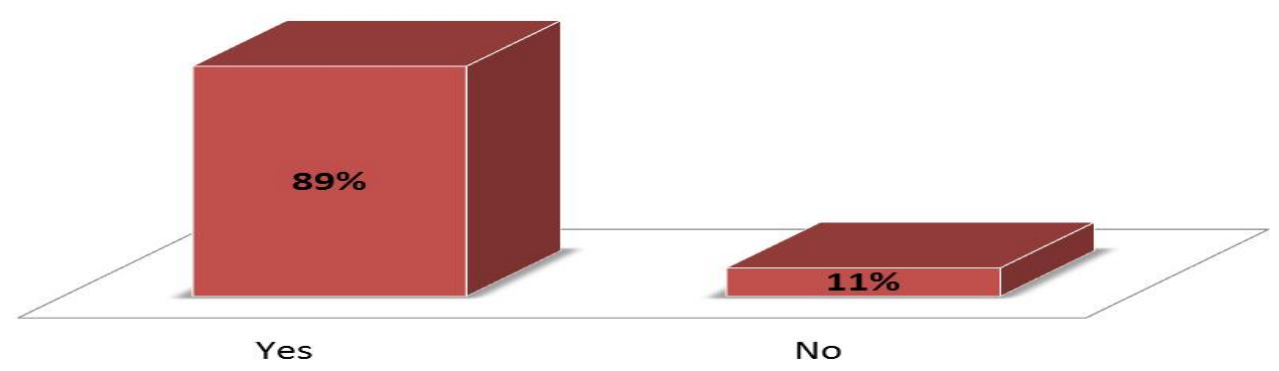




\section{Have you seen anyone did bariatric surgery, then you decided to do it ?}

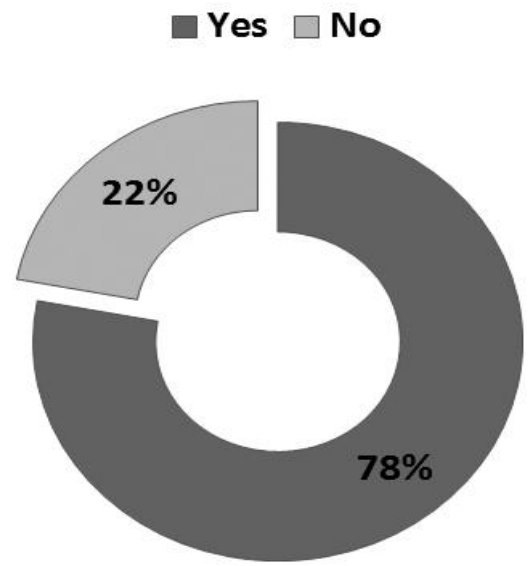

Did you advice anyone to do bariatric surgery?

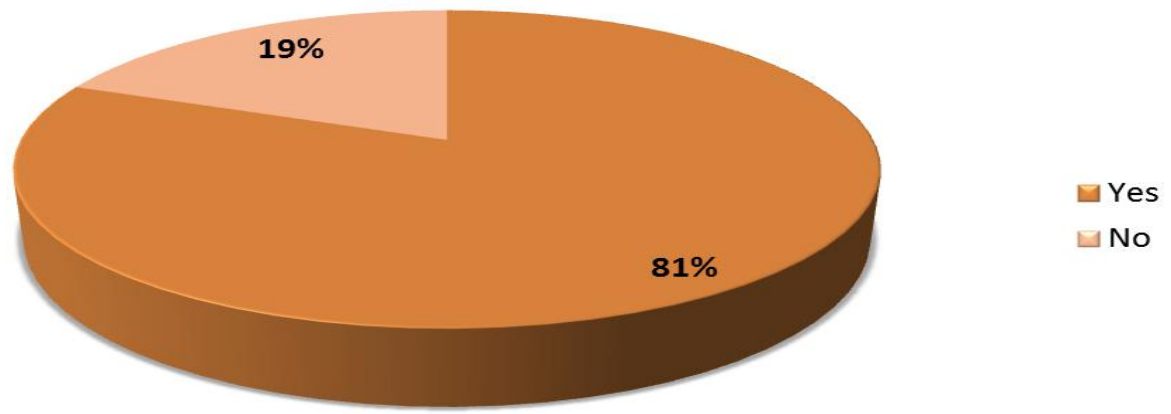

Did obesity affect your daily activities ?

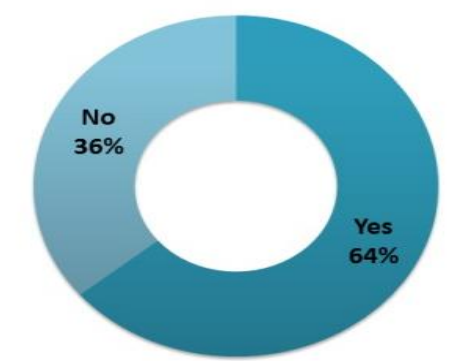

Where did you do bariatric surgery ?

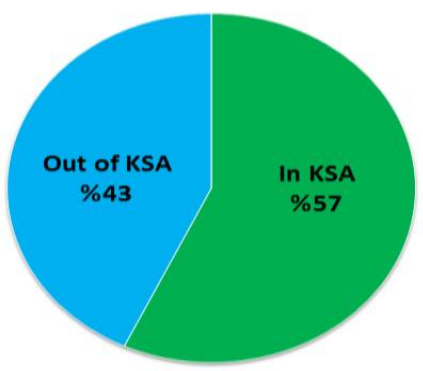

\section{Discussion:-}

In this study, we found that most of patients underwent for operation are male $57 \%$ with peak age of $20-25$, whereas the least age group those of more than 36. This gives us a hint; our society is high in obesity in age group 20-25. In 
this group age, we hope to lower the risk of obesity, thus decrease of operation and finally decrease the complication of that surgery including leaking and intestinal obstruction. There is 76 per cent of patients get advice from patients to do it, $81 \%$ per cent of patient's advice others to do it, 78 per cent of patient decided to do it after they see others did it and 89 per cent of patient have relatives of friends did the operation. All of the previous facts can really affect personality emotions, which really can push them to do it without asking doctors or read about this operation. We found that 36 per cent of patient did the operation without affecting of their obesity to their daily activities. Most of them answered, they want to lose their weight with less effort. According to American Society of Metabolic and Bariatric Surgery (ASMBS) has a list for indications of bariatric surgery is BMI $\geq 40$ or $\geq 35$ plus at least of two comorbidity related diseases, ${ }^{10}$ such as heart disease or diabetes mellitus, but we found that 10 per cent less than 31 of BMI, and 46 per cent DO NOT know how to measure BMI. Study shows 97 per cent DO NOT have heart diseases, which also NOT indication of bariatric surgery according to ASMBS. ${ }^{11}$ Fifty-nine per cent of doctors have advised patient to do bariatric surgery, but let us take it on the other hand, 41 per cent have no indication to bariatric surgery from experienced doctors. Finally, let talk a little pit of financial issue of bariatric surgery, 43 per cent of patients did it outside of Saudi Arabia who pay a lot of money, this considered as an issue to our society.

\section{Conclusion: -}

As a summary for our study, most of Saudi patients underwent for bariatric surgery DONOTfollow indication according to ASMBS or have no idea about it. Age group for this surgery is very young 20-25. Fortunately, people affecting by heart disease or diabetes mellitus is low. Male is more than those of female. Most of patients did not affected by obesity for their daily activities. Finally, above two thirds (43\%) of patients, had traveled to other countries to do that operation who pay a lot of money.

\section{Competing Interests:-}

None of the authors have any competing interests to disclose.

\section{Authors' Contribution:-}

Sultan Almutrafi contributed to study conception, design and critical revision of the paper.Yazid M. Alotaibi, Sultan Almalik,AbdulraoufAlmajhad, Waleed Almejlad and MusaedAlkhuraisi were contributed for data analysis.

\section{References:-}

1. Mokdad AH, Bowman BA, Ford ES, Vinicor F, Marks JS, Koplan JP. The continuing epidemics of obesity and diabetes in the United States.JAMA. 2002;286:1195-1200.

2. Flegal KM, Carroll MD, Kuczmarski RJ, Johnson CL. Overweight and obesity in the United States: prevalence and trends, 1960-1994. Int J Obes. 1998;22:39-47.

3. Freedman DS, Khan LK, Serdula MK, Galuska DA, Dietz WH. Trends and correlates of class 3 obesity in the United States from 1990 through 2000. JAMA. 2002;288:1758-1761.

4. Management of Overweight and Obesity.http://www.oqp.med.va.gov/cpg/OBE/OBE_base.htm.

5. NIH conference. Gastrointestinal surgery for severe obesity. Consensus Development Conference Panel. Ann Intern Med. 1991;115:956-961.

6. Livingston EH. Procedure, incidence and complication rates of Bariatric surgery in the United States. American Journal of Surgery.2004; 188:105-110.

7. MacDonald KGJ, Long SD, Swanson MS, et al. The Gastric Bypass Operation Reduces the Progression and Mortality of Non-Insulin-Dependent Diabetes Mellitus. J Gastrointest Surg. 1997;1:213-220.

8. Pories WJ, Swanson MS, MacDonald KG, et al. Who would have thought it? An operation proves to be the most effective therapy for adult-onset diabetes mellitus. Ann Surg. 1995;222:339-350.

9. Rubino F, Gagner M. Potential of surgery for curing type 2 diabetes mellitus. Ann Surg. 2002;236:554-559.

10. Benotti PN, Bistrain B, Benotti JR, Blackburn G, Forse RA. Heart disease and hypertension in severe obesity: the benefits of weight reduction. Am J ClinNutr. 1992;55:586S-590S.

11. Carson JL, Ruddy ME, Duff AE, Holmes NJ, Cody RP, Brolin RE. The effect of gastric bypass surgery on hypertension in morbidly obese patients [published erratum appears in Arch Intern Med 1994 Aug 8;154 15:1770] Arch Intern Med. 1994;154:193-200.

12. Sugerman HJ, Wolfe LG, Sica DA, Clore JN. Diabetes and hypertension in severe obesity and effects of gastric bypassinduced weight loss. Ann Surg. 2003;237:751-756. 